Research grants, sources of ideas and the effects on academic research

Hanna Hottenrott and Cornelia Lawson

DEPARTMENT OF MANAGERIAL ECONOMICS, STRATEGY AND INNOVATION (MSI) 


\title{
Research Grants, Sources of Ideas and the Effects on Academic Research*
}

\author{
Hanna Hottenrott ${ }^{\mathrm{a}, \mathrm{b}}$ and Cornelia Lawson ${ }^{\mathrm{c}, \mathrm{d}}$
}

June 2012

\begin{abstract}
Based on a sample of research units in science and engineering at German universities, this study reports survey evidence showing that research grants impact research content. Research units that receive funds from industry are more likely to source ideas from the private sector. The higher the share of industry funding on the units' total budget, the more likely that large firms influenced the research agenda. Public research grants, on the other hand, are associated with a higher importance of conferences and scientific sources. What is more, the different sources of ideas impact scientific output. Research units that source research ideas from small and medium-sized firms (SMEs) patent more, but not more successful than others in terms of the impact of their inventions on future patents. If, on the other hand, research units source ideas from large firms we find them to publish less and with lower impact on future scientific work.
\end{abstract}

Keywords: $\quad$ University Research, Scientific Productivity, Research Funding, Academic Patents, Technology Transfer

JEL-Classification: C23, I23, O31, O34, O38

${ }^{a}$ K.U.Leuven, Dept. of Managerial Economics, Strategy and Innovation, Naamsestraat 69, 3000 Leuven, Belgium and

${ }^{\mathrm{b}}$ Centre for European Economic Research (ZEW), L7, 1, 68168 Mannheim, Germany

hanna.hottenrott@econ.kuleuven.be; Tel: +32 (0)16 3257 93; Fax: +32 (0)16 326732

${ }^{\mathrm{c}}$ BRICK, Collegio Carlo Alberto, Via Real Collegio 30, 10024 Moncalieri (Turin), Italy and

${ }^{\mathrm{d}}$ University of Turin, Department of Economics S. Cognetti de Martiis, Via Po 53, 10124 Turin, Italy cornelia.meissner@unito.it; Tel: +39 011670 3857; Fax: +39 0116703895

\footnotetext{
*We are grateful to the Centre for European Economic Research (ZEW) for providing the survey data and to Thorsten Doherr for help with retrieving the patent data. We thank Paula Stephan and Dirk Czarnitzki for helpful comments. Hanna Hottenrott gratefully acknowledges financial support from the Research Foundation Flanders (FWO) and Cornelia Lawson support from the European Commission (FP7) Project \#266588, a Collegio Carlo Alberto Project (Researcher Mobility and Scientific Performance) and through a COST-STRIKE Short-Term Scientific Mission Grant.
} 


\section{INTRODUCTION}

Since the early 1980s, there has been an academic and policy debate about the role and the consequences of university-industry interactions. The interest in these issues has triggered a substantial body of conceptual and empirical studies. This previous work identified and studied numerous forms of interactions that occur between academe and industry. Most of these studies, however, take the perspective of the firm and point out channels through which the private sector sources know-how from science and benefits from it (e.g. Nelson 1986; Jaffe 1998; Mansfield 1995, 1998; Narin et al. 1997; Hall et al. 2000; Salter and Martin 2001). The common underlying idea in this stream of research is that university research

creates and expands the pool of ideas from which private sector firms draw when searching for solutions and for new technological challenges (see e.g. Fleming and Sorenson 2004). Few studies, however, have taken the perspective that academic researchers may actively source ideas from industry shaping their research agendas (e.g. Agrawal and Henderson 2002). Continuous and even occasional close interactions, for instance in the form of joint research, contract research and consulting, likely have a lasting impact on both parties involved.

The current study aims to fill this gap in the literature using data from university research units in Germany to study the relationship between research funding, sources of ideas and research productivity. In the following analysis we investigate if and how research funding, in particular project based "third-party funding" relates to the channels through which university researchers source ideas. We thereby distinguish between traditional scientific sources, institutional and industrial sources. Furthermore, we study the influence of different sources of ideas on research productivity in terms of publications in scientific journals and patents. Recent studies argued for a direct relationship between research grants and research outcome, but left channels through which academics' source ideas unexplored (e.g. Blumenthal et al. 1996; Geuna 1997; Manjarrés-Henríquez et al. 2008; Hottenrott and Thorwarth 2011; BanalEstanol et al. 2012; Lawson 2012). Some of this previous research suggested that the share of industry funding negatively affects publication output in subsequent periods. This, however, did not allow one to differentiate if this effect was due to time constraints of the researchers involved in industry funded projects, non-disclosure clauses, or due to an impact on the research content that leads to research agendas that are more in line with industry interests than with scientific relevance. Therefore, the following analysis aims at graining out the effect stemming from the "idea sourcing" argument. That is, we investigate whether research funding is indeed associated with "idea sourcing" that impacts research agendas. 
Estimating simultaneous equation models, our results support this hypothesis. First, we find that the higher the share of the research units' funding from industry, the higher the likelihood that units source ideas from industry partners, especially from large firms.

Second, taking into account unobserved heterogeneity we estimate count data Poisson models that show that these different sources impact research productivity. In particular, research units sourcing ideas from large firms, show lower publication rates as well as fewer citations per publication in the seven years following the survey. We do not find such a negative effect on publications from sourcing ideas from small and medium-sized firms (SMEs). Contrarily, we even observe a positive effect on the number of patents on which the professor was listed as inventor if ideas were sourced from SMEs while ideas from large firms result in fewer patents.

The following section summarizes relevant thoughts from the literature and presents our hypotheses regarding the role of research grants in stimulating research agendas. Section 3 derives our hypotheses on how sources of ideas may impact research productivity. Section 4 describes the data and section 5 sets out the econometric framework and presents the results. Section 6 concludes.

\section{RESEARCH GRANTS AND RESEARCH CONTENT}

Very few studies directly address the role of grants and sponsorship on university research content. Previous research mostly takes the perspective of the firms involved. Survey-based evidence by Cohen et al. (2002), for instance, shows the that the key channels through which university research impacts industrial $R \& D$ besides published research articles and reports, conferences and meetings are formal and informal collaboration, contract research and consulting. Additionally, previous research found that private sector firms that source ideas from academia usually derive large benefits for their technological innovations for instance by getting access to specialized knowledge and equipment (Nelson 1986; Jaffe 1998; Mansfield 1995, 1998; Narin et al. 1997; Hall et al. 2000; Salter and Martin 2001). It is therefore not surprising that firms increasingly seek direct contact to university researchers. Sponsoring research may constitute such a direct form of gaining access to scientific knowledge. Furthermore, research funding may lead to continuous industry-science relations by making researchers more willing to collaborate and hence increase transfer of technological knowledge from science to industry which fosters and accelerates industrial innovations (Bogler 1994). The increasing share of research grants stemming from the private sector in many OECD countries provides support for this reasoning (see OECD 2009 for details). 
From the scientists' perspective, industry grants also provide an attractive source of funds supplementing 'core funding' and other public research funding. Earlier survey-based studies that asked researchers about their motivations to work with industry or the benefits of working with industry, such as Lee (2000), stress that acquiring funds and research ideas are the main motives for joint research. Likewise Mansfield (1995) concludes from his survey that a substantial number of university research projects were initiated through consulting activities with firms. This did not only apply to industry-sponsored projects. Also publicsponsored research projects were influenced by problems from industry encountered in consulting.

Slaughter and Leslie (1997) as well as Benner and Sandström (2000) argue that funding does influence the behavior of researchers, also in terms of selection of research topics, methodology and finally research orientation. Gulbrandsen and Smeby (2005) indeed observe that university researchers in Norway who attracted industry funding are more likely to describe their research as "applied" compared to researchers without industry funding. Similarly Glenna et al. (2011) find such a correlation for biotechnology scientists in the U.S. An analysis by Bozeman and Gaughan (2007) documents a positive correlation between industry grants and the "industry involvement" of university researchers and Slaughter and Rhoades (2004) argue that university researchers may be motivated to interact with private companies for reasons other than access to additional research funding, like finding potential co-authors and ideas for their research agenda. Finally, Boardman and Ponomariov (2009) study the effects of industry grants on a broad set of indictors. They conclude that additional industry grants increase the likelihood of university scientists co-authoring papers with industrial scientists for academic journals, however, provide no indication of whether this joint research is inspired by science, industry or both.

Thus, no empirical study so far analyses whether industry funds (or public grants) have a direct impact on idea sourcing. A sponsor may become a "source of ideas" through various mechanisms. Funding relationships may either come at the compromise of accepting research impulses from the sponsor usually for a joint project and/or ideas simply spill over during a funded research project and influence future research either with, but also without the explicit intention of doing so. As industry grants usually involve more than a transfer of money they may therefore also impact research more directly. Such contracts may include detailed specifications of the expected research such as precise objectives, methods or materials, separation of liabilities and the division of ownership of obtained results. 
Independently of the design of the negotiated agreement, sponsoring relationships generally also involve mutual personal contacts between university researchers and the sponsoring firm which facilitate the exchange of ideas. Public grants on the other hand usually focus on advancing public knowledge, but usually do not involve personal contacts with the sponsoring agency. Therefore, we expect

Hypothesis 1: The larger the share of a research unit's budget stemming from industry, the more likely that industry has been an important source of ideas for research at the unit.

On the other hand, we would expect a stronger correlation between public grants and traditional scientific sources of ideas. Thus,

Hypothesis 2: The larger the share of a research unit's budget stemming from public funding institutions, the more likely that traditional scientific and institutional sources have been important sources of ideas for research at the unit.

Whereas Cohen et al. (2002) find that the influence of public research on industrial R\&D is disproportionately greater for larger firms compared to medium-sized firms, we hypothesize that larger firms may have a stronger influence on the partnering university researchers' ideas. First, this may simply be explained by the larger amount of funding that is provided by larger firms. Lee (2000), for instance, finds in his surveys that benefits of industry sponsored projects in terms of funding for graduate students and lab equipment are larger if it involves large firms as they offer more research support benefits than SMEs. Consequently, one can also argue that larger benefits result in a larger influence on the research conducted at the funded research unit. Secondly, large firms may have more capacity to engage their own researchers in joint research projects as well as in the supervision of contract research and in the exchange of results. Moreover, larger firms may be inclined to leave less flexibility to the researcher as their own in-house $R \& D$ needs to be aligned with the university research. The design of research grants from SMEs thus may differ from the set-up of those with large firms. Thus, we hypothesize that

Hypothesis 3: The share of industry funding should be more decisive in explaining the influence of large firms on the research unit's research agenda than that of SMEs. 


\section{SOURCES OF IDEAS AND RESEARCH PRODUCTIVITY}

Earlier research mostly assessed quantitatively whether research outcome is affected by research sponsorship (e.g. Blumenthal et al. 1996; Manjarrés-Henríquez et al. 2008; Hottenrott and Thorwarth 2011; Banal-Estanol et al. 2012; Lawson 2012) and the results suggest that industry funding may negatively affect scientific performance in terms of publications, but may also inspire patent productivity. Public grants, on the other hand, have been found to positively affect research productivity (Carayol and Matt 2006, Hottenrott and Thorwarth 2011, Thursby and Thursby 2011). However, the analyses did not shed light on the underlying mechanisms driving these results. Although sometimes implicitly assumed, no previous study explicitly investigates whether funding indeed affects research agendas by providing a source of ideas and if the sources that inspire university research may explain the observed phenomena. While there is some evidence on the role of different sources of ideas for the productivity of industrial R\&D (see e.g. Allen 1965; Klevorick et al. 1995; Salter and Gann 2003), for university researchers the most relevant sources of inspiration have usually been assumed to be found in their scientific environment. However, in light of a changing university landscape and an increasingly blurred border between industrial research and applied university research (Mowery 1998; Auranen and Nieminen 2010), it seems obvious to assume that university research is influenced by a whole range of idea providers also outside the university and scientific community. ${ }^{1}$ In particular, in light of industry as a significant sponsor of university research, the impact of firms as sources of ideas on academic research is of key interest for research policy. Thus, we hypothesize that

Hypothesis 4: Sources of ideas affect university faculty's subsequent research in terms of quality and quantity.

However, the critical question is whether the impact of industry on research output is positive or negative. Previous literature does not univocally suggest a certain direction. One stream of literature suggests that the impact may be negative if traditional scientific sources of ideas are fully or only partially substituted with ideas from industry that result in research agendas further away from basic scientific interests. Such agendas may then have lower chances of leading to results that can be published in peer-reviewed journals resulting in a lower number

\footnotetext{
${ }^{1}$ Traditional sources of ideas may be divided in scientific and institutional sources, with the former group including scientific literature and academic conferences as well as different kinds of research-related data bases. Institutional sources thereby comprise the direct university environment, public research centers and all forms of knowledge exchange within these institutions.
} 
of academic publications. In other words, research agendas may shift from topics of scientific interest to a selection of research projects on the basis of their perceived value in the private sector and not solely on the basis of scientific progress. Increased stimulus from industry on research conducted within universities may thus also be accompanied by a shift in scientists' research agendas that result in less effort devoted to basic research. As argued by Trajtenberg et al. (1997) industry research and development (R\&D) is directed at commercial success while university research focuses on solving fundamental scientific questions. Thus research that addresses market demands may not necessarily be close to the academic research frontier which may be reflected in fewer citations per publication. Thus, we refine Hypothesis 4 to:

Hypothesis 4a: If industry is an important source of ideas for university faculty, research may be influenced such that it yields less publishable outcome, hence a negative effect on publications and/or citations per publication can be expected.

This hypothesis assumes that - at least to some degree - sourcing ideas from industry induces a "skewing problem" which diverts university research in directions of lower academic value, particularly at the cost of more basic research. If such a skewing problem exists, an increased influence of industry on research agendas may have potential long-term effects on the future development of science. Further, long-run effects from industry-inspired research projects thus may arise if the impact on the research agenda is permanent and not a temporay phenomenon. These concerns rest, however, on the presumption that there is indeed a tradeoff between research that is being disclosed in publications and more applied work that is of interest for industry (Rosenberg and Nelson 1994).

This assumption has been challenged, however, as it can be argued that if industry partners impact the researchers' scientific interests, other research at the departments may be positively influenced by the sourcing of new ideas from industry that expand their traditional research agendas (Rosenberg 1998). Additionally, researchers may utilize the industry partners' facilities in order to materialize these ideas. There have been a few theoretical papers that argue that industry can provide ideas for basic research in the sense that applied problems nurtures ideas for basic research (Thursby et al. 2007; Banal-Estanol and Macho Stadler 2010). This is in line with the notion of the "Pasteur's quadrant" where basic research efforts can also be of commercial use (Stoke 1997). Likewise Siegel et al. (2003) argue that "Some scientists explicitly mentioned that these interactions improved the quantity and quality of their basic research." Thus, industry as a source of ideas can provide a new and 
fresh perspective and thus improve academic research performance resulting in more and better publications.

Hypothesis 4b: If industry is an important source of ideas for university faculty, research may be influenced such that it yields more publishable outcome, hence a positive effect on publications can be expected.

The direction of the idea-sourcing effect may depend on the characteristics of the source. In particular differences may exist between ideas from large and small firms. Previous research found that larger firms and start-ups have a higher probability of benefiting from academic research (Mohnen and Hoareau, 2003; Cohen et al., 2002; Arundel and Geuna, 2004). Likewise, large firms may provide more ideas for applied research or for solutions to technical problems, thus reinforcing the negative effect on publication numbers if large firms provide ideas for more applied research. Small and medium-sized firms on the other hand may be more likely to substitute internal $R \& D$ with university research, especially in highly specialized technologies. This implies that smaller firms may benefit relatively more from rather basic research that complements their own application-oriented R\&D. This may be particular relevant for firms whose R\&D employees lack specific skills or resources to conduct basic research in-house or smaller firms that want to reduce the risk and costs related to it. Perkman et al. (2011) find support for that idea showing that departments with excellent researchers in physical and engineering sciences receive more income from SMEs indicating that excellence and collaboration with SMEs is positively correlated. Moreover, a qualitative study by Bjerregaard (2009) on university-industry collaborations of nine Danish universities and 19 SMEs suggests that collaboration strategies of SMEs differ from those of large firms in terms of the time-horizon of expected results. In particular, he finds that while some collaborations followed a short-term strategy aimed at achieving immediate R\&D results, SME partners relied upon a long-term strategy. These long-term strategies by SMEs that do not push for immediate marketable results may therefore induce ideas that have a lower impact on the overall research output as they may be more in line with the ex-ante research orientation of the researcher.

Moreover, the contractual design of the collaboration may differ between large firms and SMEs translating into different effects of joint research on academics' research output. Rappert et al. (1999) report that interaction between universities and SMEs usually tends to be informal, avoiding formal procedures. Large firms, on the contrary, may be more likely to use 
institutional collaborations. Similarly, recent research by Bodas-Freitas et al. (2010) stresses that firms that use personal collaborations as opposed to institutional collaborations are generally smaller. Such informal collaboration may not hinder public dissemination of research results compared to more formal contractual arrangements used by larger firms. Thus,

Hypothesis 4c: Large firms as an important source of ideas for university faculty have a stronger influence on publishable research outcome in terms of both quantity and quality than SMEs.

In disciplines like science and engineering, research outcomes may not only be measured in terms of scientific publications. Academic patenting has been increasing in recent decades (Henderson et al., 1998; Mowery and Ziedonis, 2002; Geuna and Nesta, 2006; Verspagen, 2006), not least due to the fact that universities have actively encouraged patenting and, like publications in scientific journals, patent applications disclose scientific knowledge and thus may contribute to technological advancement. University researchers may therefore engage in patenting and publishing or focus on either activity depending on their position in the academic life-cycle (Carayol 2007, Stephan et al. 2007). Previous research has shown that industry collaboration and industry support have a positive effect on such patenting activity (Hottenrott and Thorwarth 2011, Lawson 2012). Moreover, as for instance reported in Lee (2000), joint patenting also represents an important motivation for industry-science relationships. Colyvas and Powell (2006), looking at technology transfer activities at Stanford University, observe that TTOs and researchers see industry sponsors as potential partners for licensing. Ideas from industry may thus result in industry-inspired research that is more applied and of higher relevance for industry and thus be more likely to produce patentable inventions. Therefore, we would expect that

Hypothesis 5: If industry is an important source of ideas for university faculty and research is thus closer aligned to industry interests than other (basic) research, such research leads to patentable outcomes and hence to both more patent applications and more citations per patent.

In line with our previous arguments on publication output, we would similarly expect that 
Hypothesis 5a: Large firms as an important source of ideas for university faculty have a stronger influence on patentable outcome in terms of both quantity and quality than SMEs.

\section{DATA}

The empirical analysis of this paper is based on a unique dataset that combines different data sources. The core data was collected through a survey of research units at German higher education institutions in the fields of science or engineering. ${ }^{2}$ In 2000 the Centre for European Economic Research (ZEW, Mannheim) conducted a survey among a sample of research units at general universities, technical universities and polytechnic colleges ("universities of applied sciences") stratified by regions. The questionnaire addressed "head of research unit" who are in general full professors with budget and personnel responsibility. ${ }^{3}$ The overall response rate to the survey was $24.4 \%$. This survey data has been complemented with publication and patent information at the level of the unit's head covering a period before (1994-1999) and the years after the survey (2000-2007). After the elimination of incomplete records, the final sample used for the following analysis contains 663 professor-research unit observations from 46 different institutions of which 57\% are Universities (Uni), 24\% are Technical Universities (TUs) and 19\% are Universities of Applied Sciences (UAS). ${ }^{4}$

\section{Sources of ideas}

This survey data provides us with information on the "sources of ideas" as indicated by the head of the research unit. The questionnaire asked for the relevance of a set of factors for the units' research agendas in the three years preceding the survey. Respondents ranked their answer from "no relevance" to "high relevance" on a 4-point Likert-scale. The majority of professors uses several sources, yet we want to concentrate on the most important sources. In order to obtain a binary indicator of whether a particular factor had been a strong stimulus for research at the research unit, we recode these variables such that a dummy takes the value one only, if the source had been ranked to be of "high relevance". Table 1 shows descriptive statistics for these variables.

\section{Table 1: "Source of Ideas" Stimulating Research Agendas}

\footnotetext{
${ }^{2}$ These fields include physics, mathematics and computer science, chemistry and pharmaceuticals, biology and life sciences, electrical and mechanical engineering and other engineering and related fields such as geosciences.

${ }^{3}$ Usually a chair has only one professor. Larger universities, however, may also have several professors at one chair. In any case, only one is the head of the research unit.

${ }^{4}$ For each of the 16 German States (Länder), the sample comprises at least one observation.
} 


\begin{tabular}{lrrrr} 
Source Type & not relevant & $\begin{array}{c}\text { little } \\
\text { relvance }\end{array}$ & relevant & $\begin{array}{c}\text { high } \\
\text { relevance }\end{array}$ \\
\hline Small or Medium-Sized Firms (less than 250 & & & & \\
empl.) & 27.90 & 21.72 & 28.21 & 22.17 \\
Large Firms (250 empl. or more) & 22.02 & 17.35 & 31.22 & 29.41 \\
Universities & 12.22 & 12.07 & 29.11 & 46.61 \\
Public Research Centres & 24.43 & 19.61 & 29.11 & 26.85 \\
Technology Transfer Offices (TTOs) & 50.53 & 31.67 & 13.73 & 4.07 \\
Consultants & 80.84 & 15.08 & 3.47 & 0.60 \\
Exhibitions and Fairs & 42.38 & 33.79 & 17.04 & 6.79 \\
Patents & 57.62 & 24.28 & 14.48 & 3.62 \\
Academic Journals & 13.73 & 9.35 & 24.74 & 52.19 \\
Conferences, Meetings & 9.35 & 7.54 & 24.43 & 58.67 \\
Internet, Media, other Data Bases & 17.95 & 16.14 & 32.58 & 33.33 \\
\hline *In percent based on 663 observations. Category “others” not displayed in the Table. If professors specified \\
„others“, we assigned these answers to one of the categories. If that was not possible, the observation was \\
dropped from the sample. \\
\multicolumn{4}{c}{}
\end{tabular}

Least relevant sources for research are consulting and, for many professors, also patents. Most important sources are conferences, academic journals and the university environment. We conducted a factor analysis, using the maximum-likelihood factor method, to group these eleven sources into a smaller number of (unobserved) aggregate factors.

This analysis suggested three groups that can be labeled "Scientific Sources", "Institutional Sources", and "Industry Sources" (see Table A.1 for details on the factor loadings). Scientific sources include Academic Journals, Conferences and Meetings, as well as Internet, Media and Data Bases. The second category comprises Universities and Public Research Centers as sources of research. The third group, includes large firms, SMEs, TTOs, exhibitions, and trade fairs.

"Consulting" and "Patents" as sources of ideas did not load highly on any factor, especially in the factor analysis of the binary indicator. For the purpose of our analysis we therefore decided to consider them as separate categories. Taking into account that multiple answers were possible, we find that $67.6 \%$ and $52.8 \%$ of professors named scientific sources and institutional sources as being of high relevance, respectively. Still, $42.1 \%$ regarded industry sources of high importance for shaping their research agenda (see Table 2). About $85 \%$ of professors indicate at least one source as particularly important and about 54\% named more than two sources. $43 \%$ considered scientific and institutional, but not industry as important whereas it was the opposite for only 9\%. Roughly one third of professors in the sample considered both traditional scientific and institutional sources as well as industry as highly relevant. 


\section{Research Funding}

The survey provides information on the amount and composition of funding, including "thirdparty funding" received in 1999 in addition to the research units' core funding. In the final sample $63 \%$ of professors stated that they had received funding from industry and $81 \%$ had acquired public research grants in addition to their core funding. The amount of industry funding (INDFUND) and its share over the total budget (INDSHARE) at the level of the research unit differ between institution types and research fields (see Table A.3). On average this share was $8.7 \%$ amounting to about 113 thousand Euros. The share of research grants from public sources over total budget (GOVSHARE) is comparable between universities and technical universities, but is considerably lower at UAS. ${ }^{5}$ On average, research units received $22.6 \%$ of their total budget from public research grants, which corresponds to 159 thousand Euros.

\section{Professor, research unit and university characteristics}

The average university (or technical university or university of applied sciences) had 18,220 registered students (UNISIZE) in the survey year. We include a control for institution size in our analysis in order to capture effects of better networking opportunities and scale effects in research that may affect both sources of ideas as well as research productivity.

Additionally we control for research unit size by counting the number of staff per research unit (LABSIZE), which is about 22 on average (median 13). The share of team members with a non-scientific, but technical background (TECHS) is 10.2 on average. A higher share of nonacademic personnel may for instance increase scientific productivity by reducing the professors' administrative burden as well as taking over coordination with collaboration partners, and research assistance in carrying out routinized experiments etc.

The share of advanced scientists includes researchers with at least a $\mathrm{PhD}$ degree (SENIORSTAFF) and is expected to reflect scientific capability and research capacity.

The average number of years in academe (EXPERIENCE), i.e. years since completion of $\mathrm{PhD}$, is about 22 years (also median of 22). Information on the year in which professors received their PhDs was gathered from the German National Library. ${ }^{6}$ Although professors are rather homogenous in their career position as they are all head of a research unit, we still want to

\footnotetext{
${ }^{5}$ It should be noted that the sum of INDFUND and GOVFUND is 'total third-party funding' and not the total budget. Adding this to the 'core' institutional funding (COREFUND) yields the units' overall funding: TOTALFUND = INDFUND + GOVFUND + COREFUND.

${ }^{6}$ In Germany a dissertation is recorded in the German National Library (Deutsche Nationalbibliothek). For a few professors, who according to their CVs either obtained their doctoral degree abroad or do not have a PhD, we used the year of their first publication as a proxy for the beginning of their academic career. If professors with very common names like "Müller" or "Fischer" and also common first names appeared in our dataset, we preferred to drop these observations from our dataset since publication and/or patent data could not be uniquely identified.
} 
control for some life cycle effects (Van Dalen 1998, Thursby et al. 2007, Carayol 2007, Stephan et al. 2007).

We further know from the survey whether a professor had contact with his institution's Technology Transfer Office (TTO). As it is conceivable that such contacts may impact both stronger technology transfer awareness and the administrative burden of industry and other external relations, it may also have effects on patenting and publishing activities. The number of female professors is small with only 21 of the 633 professors in our sample. However, we still want to control for gender differences as recent research found men and women to differ in their collaborator choice strategies (Bozeman and Gaughan 2011), which may also affect idea sourcing. Table 2 provides summary statistics for the main variables of interest.

Table 2: Summary statistics (663 obs.)

\begin{tabular}{|c|c|c|c|c|c|}
\hline Aggregate Sources of Ideas (binary) & Variable & Mean & Std. Dev. & Min & Max \\
\hline Scientific Sources & SCIENCE & 0.676 & 0.468 & 0 & 1 \\
\hline Industry Sources & INDUSTRY & 0.421 & 0.494 & 0 & 1 \\
\hline Institutional Sources & INSTITUTIONS & 0.528 & 0.500 & 0 & 1 \\
\hline \multicolumn{6}{|l|}{ Funding: } \\
\hline Amount Ind. Funding $(\mathrm{T} €)$ & $I N D F U N D$ & 113.48 & 273.7433 & 0 & $2,539.556$ \\
\hline $\begin{array}{l}\text { Share of Ind. Funding in } \% \text { of Total } \\
\text { Budget }\end{array}$ & INDSHARE & 8.715 & 13.440 & 0 & 100 \\
\hline Amount Gov. Grants ( $\mathrm{T} €$ ) & GOVFUND & 158.064 & 439.851 & 0 & $7,008.703$ \\
\hline $\begin{array}{l}\text { Share of Gov. Grants in \% of Total } \\
\text { Budget }\end{array}$ & GOVSHARE & 22.584 & 20.042 & 0 & 100 \\
\hline \multicolumn{6}{|l|}{ Controls: } \\
\hline Institution size ( total \# students) & STUDENTS & $18,219.70$ & $11,819.43$ & 1,451 & 59,599 \\
\hline Number of people in lab (FTEs) & LABSIZE & 22.234 & 31.12 & 1.2 & 300 \\
\hline Number of years since $\mathrm{PhD}$ & EXPERIENCE & 21.872 & 8.68 & 1 & 43 \\
\hline Contact to TTO dummy & TTO & 0.738 & 0.440 & 0 & 1 \\
\hline$\%$ technical employees & TECHS & 10.203 & 13.773 & 0 & 80 \\
\hline \% employees $\mathrm{PhD}$ & SENIORSTAFF & 72.259 & 16.988 & 3.333 & 100 \\
\hline University & $U N I$ & 0.573 & 0.495 & 0 & 1 \\
\hline Technical University & $T U$ & 0.237 & 0.425 & 0 & 1 \\
\hline University of Applied Sciences & $U A S$ & 0.190 & 0.393 & 0 & 1 \\
\hline Female Professor dummy & GENDER & 0.032 & 0.175 & 0 & 1 \\
\hline
\end{tabular}

*Six scientific field dummies not presented. See Table A.2 in the Appendix.

\section{Patent and Publication data}

We supplemented the survey data with patent and publication information at the level of the head of the research unit. Patent and publication records of the responding professor is 
thereby assumed to proxy the research output of his research unit. ${ }^{7}$ Patent information was drawn from the data base of the German Patent and Trademark Office (DPMA). In particular, we searched through this database for all patents, which listed professors from our sample as inventors. We further retrieved "forward citations" to these patents, that is, the number of citations received by each patent after filing. Forward citations have been shown to be suitable measures for quality, importance or significance of a patented invention and have been used in several studies (see e.g. Henderson et al. 1998; Hall et al. 2001; Czarnitzki et al. 2009).

The publication track records of professors were collected via the ISI Web of Science ${ }^{\circledR}$ database of Thomson-Scientific (Philadelphia, PA, USA). This database covers all significant document types within a comprehensive collection of academic journals. We searched for publications (articles, notes, reviews and letters) of professors in our sample through the ISI Web of Knowledge ${ }^{\circledR}$ platform by name. Subsequently we manually filtered the results on the basis of affiliations, addresses and research fields. In order to assign publications correctly to professors, we further collected information on their career paths in order to relate publication records to professors even if the affiliation stated on the publication did not correspond to the professor's current affiliation. Like for patents, we collected the number of citations for each publication. Despite some limitations (van Dalen and Klamer 2005) several authors have shown, that citation counts are an adequate indicator to evaluate research output (Garfield and Welljams-Dorof 1992; Baird and Oppenheim 1994). ${ }^{8}$

All patents, publications and citations were collected from the professor's first entry until the end of 2007. For our main analysis, we limited the time horizon to the period from 1994 to 2007. This corresponds to an "activity window" of six years before (1994-1999) and eight years after the survey (2000-2007). Table 3 provides descriptive statistics for these variable split into the two activity windows. Like common for publication output, a relatively small number of professors is responsible for the majority of publications (see e.g. Stern and Jensen 1983).

\footnotetext{
${ }^{7}$ Even though we do know the number of each chair's employees and details on their qualification, we do not have further details (e.g. name) of the individual team members. Thus, we cannot collect publication and patent information at the team member level and use the publications (and patents) of the head of the research unit justified on the basis that in science and engineering at German institutions it is common practice to include the 'head' on every publication co-authored by his unit's members.

${ }^{8}$ The popular impact factor of the journal in which an article was published would also have been available, but since we study different fields of science, journal impact factors have been shown to be less appropriate (see Amin and Mabe 2000).
} 
$11 \%$ did not publish in relevant field journals as included in the ISI database and $44 \%$ had not applied for any patent. $10 \%$ of professors published nearly $42 \%$ of the total number of 32,971 publications. The same is true for citations: there are very few highly cited professors and $10 \%$ of publications received no citation at all. On the other hand, there are professors with more than 10,000 total citations or more than 182 citations per paper. For patent applications and citations, we see a similar picture. $10 \%$ of professors account for about a quarter of the 3,010 patent applications. The fact that not all patent applications are successful has to be taken into account when looking at the mean of patent forward citations which indicates that two-thirds of patent applications did not receive any citations. (See Table A.3 in the appendix for publication and patenting numbers by research field.)

Table 3: Scientific Output (663 obs.)

\begin{tabular}{llrrrr}
\hline Scientific Output 1994-1999: & & & & & \\
\hline Publications & PUB $_{1994-1999}$ & 11.329 & 20.573 & 0 & 243 \\
Average Citations per Publication & CITperPUB $_{1994-1999}$ & 11.586 & 20.201 & 0 & 210.96 \\
Patents & PAT $_{1994-1999}$ & 1.388 & 3.447 & 0 & 32 \\
Average Citations per Patent & CITPAT $_{1994-1999}$ & 3.918 & 17.436 & 0 & 219.50 \\
\hline Scientific Output 2000-2007: & & & & & \\
\hline Publications & PUB $_{2000-2007}$ & 18.79 & 30.659 & 0 & 211 \\
Average Citations per Publication & CITperPUB $_{2000-2007}$ & 5.493 & 7.324 & 0 & 42.45 \\
Patents & PAT $_{2000-2007}$ & 1.371 & 3.475 & 0 & 36 \\
Average Citations per Patent & CITperPAT $_{2000-2007}$ & 0.209 & 0.843 & 0 & 14.75 \\
\hline
\end{tabular}

\section{EMPIRICAL ANALYSIS}

The following empirical analysis takes place in two parts. First, we study the effects of research grants on sources of ideas. Thus, we want to shed light on the correlations between grants from private and public sector sources and the different sources of ideas as outlined in the beginning of the previous section. We hypothesize, as described in section 2 , that grants and contracts affect the relevance of different sources of ideas controlling for university and research unit characteristics (STUDENTS, LABSIZE, EXPERIENCE, TECHS, SENIORSTAFF, PUB ${ }_{1995-}$ 1999, $P A T_{1995-1999}$ and GENDER).

The second part of the analysis aims at shedding light on how different sources of ideas affect research productivity. As potential effects are unlikely to show up immediately, we observe the scientific output up to eight years after the survey. We thus expect journal publication output and patent applications in the post-survey period 2000-2007 to be a function of sources of ideas that shape the research agenda (SCIENCE, INSTITUTIONS, INDUSTRY) and past 
publication and patenting efforts $\left(P U B_{1995-1999}, P A T_{1995-1999}\right)$, as past performance is likely to affect future performance due to a ,cumulative advantage“. Additionally, lab size (LABSIZE), experience (EXPERIENCE), and the skill composition at the lab in terms of the percentage of technical employees (TECHS) and senior researchers (SENIORSTAFF) may affect scientific productivity. Further, we consider attributes such as the research field, the type of institution and gender as control variables in the econometric models to be estimated. Finally, as publication or patent output may not only be affected in terms of quantity, but also quality, we estimate the effects on average citations per publication and patent (CITperPUB, CITperPAT).

\subsection{Econometric set-up}

\subsubsection{Research funding and sourcing ideas}

We estimate $n$-equation multivariate probit models ( $h=5$ and 8 , respectively) that can be written as:

$$
\begin{aligned}
y_{m}^{*} & =x_{m} \beta_{m}+\varepsilon_{m}, \quad m=1, \ldots, h \\
y_{m} & =D\left(y_{m}^{*}>0\right), \quad m=1, \ldots, h \\
\epsilon & =\left(\varepsilon_{1}, \ldots \varepsilon_{h}\right)^{\prime} \sim N(0, \Sigma)
\end{aligned}
$$

where $m$ represents the different sources of ideas. The variance-covariance matrix $\sum$ has values of 1 on the diagonal due to normalization and correlations $\rho_{\mathrm{jk}}=\rho_{\mathrm{kj}}$ as off-diagonal elements. The log-likelihood function is then given by:

$$
\ln L=\left(\beta_{1}, \ldots \beta_{h}\right), \Sigma ; y \mid x=\sum_{i=1}^{N} \ln \Phi_{h}\left(\left(q_{i, 1}, x_{i, 1} \beta_{1}, \ldots, q_{i, h}, x_{i, h} \beta_{h}\right) ; \Omega\right)
$$

where $q_{i, m}=2 y_{i, m}-1$.

The matrix $\Omega$ has values of 1 on the diagonal and $\omega_{j, k}=\omega_{k, j}=q_{i, j} q_{i, k} \rho_{i, k}$ for $j \neq k$ and and j,k $=(1, \ldots, \mathrm{h})$ as off-diagonal elements. $\Phi_{h}$ denotes the joint normal distribution of order $h$. The expression for the log-likelihood function thus involves an $h$-dimensional integral that does not have a closed form. It can be evaluated numerically through simulation. We employ Maximum Simulated Likelihood Method using the GHK simulator (Geweke 1989, Hajivassiliou and McFadden 1998, and Keane 1994). For a detailed description of simulation methods we also refer to Train (2009). We use the user-written command $\mathrm{cmp}$ in Stata to estimate the multivariate probit models (see Roodman 2009). ${ }^{9}$

\footnotetext{
${ }^{9}$ The simulation method requires to draw random variables from an upper-truncated normal distribution. We employ draws based on Halton sequences as they are more effective for simulated MSL estimation than pseudorandom draws (Train 2009).
} 
We estimate two specifications of our main model of which the results are presented in Table 4 and 5, respectively. ${ }^{10}$ As can be gathered from Table 4, the share of funding stemming from the private sector (INDSHARE) is significantly positive only in the INDUSTRY-equation, pointing to a positive relationship between funding from industry and sourcing research ideas from industry partners that stimulate research at the unit. This confirms Hypothesis 1. Grants from the public sector, on the other hand, is associated with ideas stimulated by traditional scientific sources and scientific institutions confirming Hypothesis 2. The control variables show a diverse picture across the different sources of ideas. The equation for consultants did not yield any informative insights and will be henceforth omitted from the next specification presented in Table 5. In the model presented in Table 5, we distinguish industry sources by firm size, i.e. large firms and SMEs to gain insights on which factor(s) inside the industry group drives the result. ${ }^{11}$ Other potential sources that were categorized as industry sources before were TTOs as intermediaries between universities and industry partners and exhibitions and trade fairs. The latter two were subsumed in the group labeled R_INDUSTRY as presented in column 5 of Table 5. The results show that the positive relationship between industry funding and idea stimulus was driven by larger firms rather than SMEs confirming Lee (2000) and our Hypothesis 3. However, we also see that public grants can be associated with ideas from large firms confirming findings by Mansfield (1995), to a much smaller extent however. This effect may also be rooted in public grants for university-industry collaborations. The results further suggest that research units with a higher share of industry funding are less likely to source ideas from their institutional surrounding. In both models pre-sample publication performance is positively associated with sourcing ideas from the institutional environment, which may be explained by the presentation of research results in seminars and subsequent discussions between researchers that stimulate ideas especially for actively publishing professors. Not surprisingly, patenting professors are more likely to source ideas from patent applications than non- or occasional patenting faculty. Female professors also tend to source ideas from their institutional surrounding and the share of technical staff is positively correlated with sourcing ideas from patents and institutions. The share of senior staff at the research unit is negatively related to large firms as source of ideas which may be explained by the outflow of graduated research to industry especially of those

\footnotetext{
${ }^{10}$ It should be noted that we also estimated ordered Probit models on the original categories of the dependent variables. The results confirmed the findings of the binary models. Furthermore, we estimated the models using not the budget share (INDSHARE, GOVSHARE), but the logged amounts (INDFUND, GOVFUND). As the results were very similar, we refrain from presented these in detail.

11 The Correlation coefficients between the equations in the MV-probit are displayed in Table A.3 in the Appendix. Significant correlation between several of the equations support estimation of a simultaneous equation model.
} 
units actively involved with firms. Industry also turned out to be a particularly interesting source of ideas for professors that published less in the past. The effect, however, is more pronounced for large firms as compared to SMEs.

Table 4: Simultanous Probit regression results (marginal effects) on "sources of ideas" (663 obs.)

\begin{tabular}{|c|c|c|c|c|c|}
\hline & SCIENCE & INSTITUTIONS & INDUSTRY & PATENTS & CONSULTANTS \\
\hline \multirow[t]{2}{*}{ INDSHARE } & 0.0001 & -0.0022 & $0.0106 * * *$ & 0.0001 & 0.0000 \\
\hline & $(0.0009)$ & $(0.0014)$ & $(0.0018)$ & $(0.0001)$ & $(0.0000)$ \\
\hline \multirow[t]{2}{*}{ GOVSHARE } & $0.0014 * * *$ & $0.0050 * * *$ & 0.0005 & -0.0002 & 0.0000 \\
\hline & $(0.0004)$ & $(0.0005)$ & $(0.0009)$ & $(0.0002)$ & $(0.0001)$ \\
\hline \multirow[t]{2}{*}{ STUDENTS } & 0.3624 & 0.4186 & 0.1194 & -0.0330 & 0.0005 \\
\hline & $(0.3081)$ & $(0.3792)$ & $(0.4202)$ & $(0.0255)$ & $(0.0026)$ \\
\hline \multirow[t]{2}{*}{ STUDENTS ${ }^{2}$} & -0.0192 & -0.0190 & -0.0081 & $0.0024 * *$ & 0.0000 \\
\hline & $(0.0152)$ & $(0.0181)$ & $(0.0222)$ & $(0.0012)$ & $(0.0001)$ \\
\hline \multirow[t]{2}{*}{$L A B S I Z E$} & $0.0739 * *$ & 0.0043 & $0.1040 * * *$ & -0.0015 & 0.0004 \\
\hline & $(0.0263)$ & $(0.0091)$ & $(0.0321)$ & $(0.0061)$ & $(0.0015)$ \\
\hline \multirow[t]{2}{*}{$L A B S I Z E^{2}$} & 0.0000 & $0.0000 * * *$ & 0.0000 & 0.0000 & 0.0000 \\
\hline & $(0.0000)$ & $(0.0000)$ & $(0.0000)$ & $(0.0000)$ & $(0.0000)$ \\
\hline \multirow[t]{2}{*}{ EXPERIENCE } & -0.0021 & 0.0040 & -0.0065 & $0.0024 *$ & -0.0005 \\
\hline & $(0.0169)$ & $(0.0042)$ & $(0.0087)$ & $(0.0014)$ & $(0.0013)$ \\
\hline \multirow[t]{2}{*}{ EXPERIENCE $E^{2}$} & -0.0001 & $-0.0002 * *$ & 0.0000 & 0.0000 & 0.0000 \\
\hline & $(0.0003)$ & $(0.0001)$ & $(0.0002)$ & $(0.0000)$ & $(0.0000)$ \\
\hline \multirow[t]{2}{*}{ TECHS } & -0.0008 & $0.0031 * * *$ & -0.0007 & $0.0006 * * *$ & 0.0000 \\
\hline & $(0.0022)$ & $(0.0003)$ & $(0.0025)$ & $(0.0002)$ & $(0.0001)$ \\
\hline \multirow[t]{2}{*}{ SENIORSTAFF } & -0.0012 & $0.0023 * * *$ & $-0.0044 * * *$ & $0.0002 * * *$ & 0.0000 \\
\hline & $(0.0012)$ & $(0.0003)$ & $(0.0009)$ & $(0.0001)$ & $(0.0001)$ \\
\hline \multirow[t]{2}{*}{$P U B_{1995-1999}$} & 0.0005 & $0.0017 * * *$ & $-0.0025 * *$ & 0.0000 & 0.0000 \\
\hline & $(0.0015)$ & $(0.0004)$ & $(0.0011)$ & $(0.0001)$ & $(0.0000)$ \\
\hline \multirow[t]{2}{*}{$P A T_{1995-1999}$} & -0.0018 & $-0.0155 * * *$ & 0.0083 & $0.0031 * * *$ & -0.0003 \\
\hline & $(0.0027)$ & $(0.0039)$ & $(0.0100)$ & $(0.0003)$ & $(0.0008)$ \\
\hline \multirow[t]{2}{*}{ GENDER } & 0.0176 & $0.1821 * * *$ & -0.0409 & 0.0146 & - \\
\hline & $(0.0520)$ & $(0.0369)$ & $(0.1430)$ & $(0.0110)$ & - \\
\hline \multicolumn{2}{|l|}{ Log-Likelihood } & \multicolumn{2}{|c|}{$-1,178.97$} & & \\
\hline \multicolumn{2}{|c|}{ Joint sign. of field dummies } & \multicolumn{2}{|c|}{2.75} & & \\
\hline \multicolumn{2}{|c|}{ Joint sign. of inst. type dummies } & \multicolumn{2}{|c|}{$12.55 * * *$} & & \\
\hline
\end{tabular}


Table 5: Simultanous Probit regression results (marginal effects) on "sources of ideas" with industry sources divided by firm size (663 obs.)

\begin{tabular}{|c|c|c|c|c|c|c|}
\hline & SCIENCE & INSTITUTIONS & LARGE FIRMS & SMEs & R_INDUSTRY & PATENTS \\
\hline \multirow[t]{2}{*}{ INDSHARE } & 0.0000 & $-0.0024 * *$ & $0.0071 * * *$ & 0.0025 & 0.0003 & 0.0000 \\
\hline & $(0.0011)$ & $(0.0012)$ & $(0.0027)$ & $(0.0023)$ & $(0.0004)$ & $(0.0001)$ \\
\hline \multirow[t]{2}{*}{ GOVSHARE } & $0.0010 * * *$ & $0.0047 * * *$ & $0.0004 * * *$ & -0.0004 & 0.0002 & -0.0001 \\
\hline & $(0.0003)$ & $(0.0006)$ & $(0.0001)$ & $(0.0006)$ & $(0.0006)$ & $(0.0002)$ \\
\hline \multirow[t]{2}{*}{ STUDENTS } & 0.3530 & 0.5173 & -0.4053 & 0.2652 & $-0.3601 * * *$ & $-0.0389 * *$ \\
\hline & $(0.3422)$ & $(0.3854)$ & $(0.3122)$ & $(0.3392)$ & $(0.1211)$ & $(0.0176)$ \\
\hline \multirow[t]{2}{*}{ STUDENTS ${ }^{2}$} & -0.0187 & -0.0241 & 0.0172 & -0.0145 & $0.0181 * * *$ & $0.0025 * *$ \\
\hline & $(0.0171)$ & $(0.0183)$ & $(0.0161)$ & $(0.0181)$ & $(0.0062)$ & $(0.0010)$ \\
\hline \multirow[t]{2}{*}{ LABSIZE } & 0.0544 & 0.0292 & 0.1387 & 0.0122 & 0.0123 & $-0.0241 * * *$ \\
\hline & $(0.0406)$ & $(0.0405)$ & $(0.0963)$ & $(0.1037)$ & $(0.0263)$ & $(0.0059)$ \\
\hline \multirow[t]{2}{*}{$L A B S I Z E^{2}$} & 0.0095 & 0.0019 & -0.0054 & 0.0074 & 0.0013 & $0.0045 * * *$ \\
\hline & $(0.0114)$ & $(0.0086)$ & $(0.0222)$ & $(0.0154)$ & $(0.0045)$ & $(0.0006)$ \\
\hline \multirow[t]{2}{*}{ EXPERIENCE } & -0.0039 & 0.0017 & -0.0061 & 0.0023 & 0.0012 & $0.0017 * *$ \\
\hline & $(0.0173)$ & $(0.0040)$ & $(0.0082)$ & $(0.0168)$ & $(0.0032)$ & $(0.0008)$ \\
\hline \multirow[t]{2}{*}{ EXPERIENCE ${ }^{2}$} & -0.0001 & -0.0002 & 0.0001 & -0.0001 & 0.0000 & $0.0000 *$ \\
\hline & $(0.0003)$ & $(0.0001)$ & $(0.0002)$ & $(0.0004)$ & $(0.0001)$ & $(0.0000)$ \\
\hline \multirow[t]{2}{*}{ TECHS } & 0.0004 & $0.0037 * * *$ & 0.0006 & -0.0006 & -0.0004 & 0.0005 \\
\hline & $(0.0025)$ & $(0.0003)$ & $(0.0013)$ & $(0.0019)$ & $(0.0004)$ & $(0.0001)$ \\
\hline \multirow[t]{2}{*}{ SENIORSTAFF } & -0.0016 & $0.0018 * * *$ & $-0.0040 * * *$ & -0.0020 & 0.0001 & 0.0003 \\
\hline & $(0.0014)$ & $(0.0005)$ & $(0.0011)$ & $(0.0027)$ & $(0.0006)$ & $(0.0001)$ \\
\hline \multirow[t]{2}{*}{$P U B_{1995-1999}$} & 0.0004 & $0.0017 * * *$ & $-0.0021 * *$ & $-0.0012 *$ & -0.0002 & $-0.0001 * * *$ \\
\hline & $(0.0015)$ & $(0.0002)$ & $(0.0010)$ & $(0.0007)$ & $(0.0002)$ & $(0.0001)$ \\
\hline \multirow[t]{2}{*}{$P A T_{1995-1999}$} & -0.0030 & $-0.0152 * * *$ & 0.0052 & 0.0082 & 0.0001 & $0.0029 * * *$ \\
\hline & $(0.0023)$ & (0.0039) & $(0.0077)$ & $(0.0070)$ & $(0.0014)$ & $(0.0007)$ \\
\hline \multirow[t]{2}{*}{ GENDER } & 0.0213 & $0.1839 * * *$ & 0.0088 & -0.0754 & 0.0131 & $0.0231 *$ \\
\hline & $(0.0521)$ & $(0.0353)$ & $(0.0857)$ & $(0.1000)$ & $(0.0187)$ & \\
\hline Log-Likelihood & \multicolumn{6}{|c|}{$-1,505.08$} \\
\hline Joint sign. of field dummies $\chi^{2}$ (6) & \multicolumn{6}{|c|}{0.12} \\
\hline Joint sign. of inst. type dummies $\chi^{2}$ (2) & \multicolumn{6}{|c|}{$858.34 * * *$} \\
\hline
\end{tabular}




\subsubsection{Sources of ideas and research productivity}

The previous analysis suggested that industry funding impacts a research unit's sources of ideas. In the following analysis, we test if - controlling for unobserved heterogeneity between units' heads - different sources of ideas translate into differences in research performance in subsequent years, a phenomenon that has been attributed directly to funding in previous literature (Blumenthal et al. 1996; Geuna 1997; Manjarrés-Henríquez et al. 2008; Hottenrott and Thorwarth 2011; Banal-Estanol et al. 2012). This previous work, however, did not allow to conclude whether this effect was due to time constraints of the researchers involved in industry funded projects, non-disclosure clauses, or due to an impact on the research content that leads to research agendas that a more aligned with industry interests than with scientific relevance. Thus, the following analysis is aimed at disentangling these effects by graining out the effect stemming from the "idea-sourcing" argument.

For this purpose, we estimate count data models for investigating the relationship between sources of ideas and research output. The number of publications and patent applications are by nature positive, integer values and also characterized by many zeros, as not all of the professors in our sample did publish and/or patent. The same applies for the number of citations for both measures. The estimation equation is assumed to be of an exponential functional form and can be written as:

$$
\lambda_{i t}=E\left[Y_{i, 2000-2007} \mid Z_{i, 1999}, X_{i t}, c_{i}\right]=\exp \left(\alpha Z_{i 1999}+X_{i t}^{\prime} \beta+c_{i}\right)
$$

where $Y_{i}$ is the count variable and stands either for publication counts (PUB), patent applications (PAT), or citations per item (CITperPUB, CITperPAT) by scientist $i$ within the time span 2000 to 2007. The outcome variables are assumed to be Poisson-distributed with $\lambda_{\text {it }}>0$. $\mathrm{Z}_{i, 1999}$ denotes the set of sources of ideas as outlines before. $X_{i t}$ represents the set of control variables and $\alpha$ and $\beta$ are the parameters to be estimated. $c_{i}$ is the individual specific unobserved effect, such as individual skills of each scientist or their attitude towards publishing or patenting.

A key assumption of the Poisson model is the equality of the conditional mean and the conditional variance, which is typically violated in applications leading to overdispersion. The use of negative binomial regression models may be a solution as it allows for overdispersion. However, although the negbin model relaxes this assumption of equidispersion, it is only consistent and efficient if the functional form and distributional assumption of the variance term are correctly specified. The Poisson model, on the other hand, is consistent solely under the assumption that the mean is correctly specified even if overdispersion is present. In case 
the assumption of equidispersion is violated and hence the obtained standard errors are too small, this can be corrected by using fully robust standard errors (see Wooldridge 2002).

A drawback of our cross-sectional survey data is that usually one cannot control for unobserved heterogeneity between the subjects of interests. In our case unobserved effects could be specific skills of each scientist that are positively correlated with the right hand side variables such as the sources of ideas. For instance, not all scientists may have the necessary absorptive capacities to source ideas from firms or scientific institutions other than their own. If unobserved subject-specific heterogeneity is present, the estimated coefficient of the sources of ideas variables would be upwards biased. However, we do have time-series information of the dependent variables, patents and publications. For such an advantageous case, Blundell et al. $(1995,2002)$ suggest a solution which they call "feedback model" which is based on the argument that the main source of unobserved heterogeneity lies in the different values of the dependent variable $Y_{i}$ with which observation units (professors in our case) enter the sample. Following Blundell et al. $(1995,2002)$ we can account for unobserved timeinvariant professor heterogeneity by using pre-sample information to capture unobserved heterogeneity. In particular, the model approximates the unobserved heterogeneity by including the $\log$ of the $Y_{i}$ from a pre-sample period average $\left(\ln \left[P U B_{-} M E A N\right], \ln \left[P A T \_M E A N\right]\right.$ and so forth) into a standard pooled cross-sectional model. In case $Y_{i}$ is zero in the pre-sample period, e.g. a professor had no publications, a dummy is used to capture the "quasi-missing" value in $\log Y_{i}$ in the pre-sample period $\left(d\left[P U B \_M E A N=0\right], d\left[P A T \_M E A N=0\right]\right.$ and so forth). We constructed the pre-sample mean by using six pre-sample observation values of $Y$ for the years 1994 to 1999.

The results are presented in Table 6. Model 1 shows the results on the number of publications and model 2 shows the results on the number of citations per publication. Models 3 and 4 distinguish between large firms, SMEs and other industry sources. As expected scientific sources inspire research and lead to higher productivity both in terms of quality and quantity confirming Hypothesis 4. Institutional sources, however, are not significant. Model 1 shows that research impulses from industry in general are associated with lower publication counts confirming Hypothesis $4 a$, but not with fewer citations per publication. Interestingly, when distinguishing between large firms and SMEs, it turns out that impulses from large firms reduce publication output both in terms of quantity (model 3) and quality (model 4) confirming Hypothesis $4 c$. Noteworthy, the latter effect on quality is larger than the effect on quantity. SMEs as sources of ideas have no significant impact on publication output. TTOs, exhibitions and trade fairs as summarized in INDUSTRY_R in models 3 and 4, on the other 
hand, have a positive influence on the number of publications and, although slightly weaker, on the number of citations per publication confirming Hypothesis $4 b$. The high significance of the pre-sample means of publications $\left(\ln \left[P U B_{-} M E A N\right] / \ln \left[C I T p e r P U B \_M E A N\right]\right)$ and patents (In[PAT_MEAN]/In[CITperPAT_MEAN]) underpins the importance of controlling for unobserved heterogeneity. Interestingly, both publication history as well as patent history are associated with more future publications. On the number of citations per publication however, it is only previous citations to publications that count, not citations to patents. For those control variables that are significant we find the expected signs. Older professors seem to publish less, but do not receive fewer (nor more) citations per publication. Research units that had contact to their university's TTO produce publications that receive more citations on average, however, the significance level is only $10 \%$.

The results of the Poisson models on patent output are depicted in Table 7. Like for publications we see, contrary to our Hypothesis 5, a negative effect of industry as idea stimulus on the number of patents on which the head of unit is listed as inventor. Model 3, however, reveals a more nuanced picture. Large firms stimulate research agendas that lead to fewer patents, but SMEs to more while the quality of the patents, as measured by the number of citations, is not affected. The impact of large firms is in absolute terms larger than the one of SMEs, however, only in terms of patent quantity, but not quality. Thus, Hypothesis $5 a$ is partially confirmed. This may point out differences in the nature of the sponsoring agreements between large firms and university professors compared to those with SMEs. Large firms may also use collaboration with the public sector at different stages of the R\&D process compared to SMEs. This is in line with Cohen et al. (2002) who report that large U.S. firms regard "contributing to project completion" as a more important benefit of collaborating with universities, than "suggesting new projects". This indicates that large firms may collaborate on projects which are no longer in the research stage that results in a patent (application), but are already in the development phase. Likewise, Perkmann and Walsh (2009) find in most of the applied projects in their data that academics contributed to projects that were already ongoing within the partner firms. Two thirds of the projects they study involved large firms supporting the notion that large firms may involve universities at later stages of the $R \& D$ process.

As could be expected, sourcing ideas from patents leads to more and more highly cited patents in the future. Interestingly, scientific and institutional sources of ideas do not affect the number of patents, but do affect the technological relevance of patents negatively. This may as well point to the fact that these patents are less relevant to industrial applications. 
Surprisingly, contact with the university's TTO does not affect patent quantity and quality significantly. Another interesting result is the positive significance of the pre-sample publication history on patent quality. Past patent activity, on the other hand, affects patent quantity, but not quality. 
Table 6: Estimation results Poisson Models with fixed effects on publication output (663 obs.)

\begin{tabular}{|c|c|c|c|c|}
\hline & Model 1 & Model 2 & Model 3 & Model 4 \\
\hline Variable & $P U B$ & CITperPUB & $P U B$ & CITperPUB \\
\hline \multirow[t]{2}{*}{ SCIENCE } & $0.075 *$ & $0.094 *$ & $0.081^{* *}$ & 0.095 \\
\hline & $(0.045)$ & $(0.057)$ & $(0.042)$ & $(0.062)$ \\
\hline \multirow[t]{2}{*}{ INSTITUTIONS } & -0.002 & 0.012 & -0.025 & 0.007 \\
\hline & $(0.058)$ & $(0.063)$ & $(0.063)$ & $(0.064)$ \\
\hline \multirow[t]{2}{*}{ INDUSTRY } & $-0.052 * * *$ & -0.063 & & \\
\hline & $(0.007)$ & $(0.044)$ & & \\
\hline \multirow[t]{2}{*}{ LARGE FIRMS } & & & $-0.088 * * *$ & $-0.141 * *$ \\
\hline & & & $(0.022)$ & $(0.066)$ \\
\hline \multirow[t]{2}{*}{ SMES } & & & -0.024 & 0.013 \\
\hline & & & $(0.051)$ & $(0.048)$ \\
\hline \multirow[t]{2}{*}{ PATENTS } & 0.022 & -0.007 & -0.024 & -0.013 \\
\hline & $(0.055)$ & $(0.040)$ & $(0.051)$ & $(0.029)$ \\
\hline \multirow[t]{2}{*}{ CONSULTANTS / INDUSTRY_R } & $-0.166^{* * *}$ & $0.064 * *$ & $0.092 * *$ & $0.072 *$ \\
\hline & $(0.028)$ & $(0.030)$ & $(0.044)$ & $(0.032)$ \\
\hline \multirow[t]{2}{*}{ STUDENTS } & 2.572 & -2.214 & 2.999 & -1.859 \\
\hline & $(1.702)$ & (1.599) & $(1.835)$ & $(1.882)$ \\
\hline \multirow[t]{2}{*}{ STUDENTS2 } & -0.124 & 0.126 & -0.149 & 0.106 \\
\hline & $(0.086)$ & $(0.081)$ & $(0.093)$ & $(0.097)$ \\
\hline \multirow[t]{2}{*}{$L A B S I Z E$} & 0.395 & 0.007 & 0.417 & 0.025 \\
\hline & $(0.301)$ & $(0.321)$ & $(0.315)$ & $(0.358)$ \\
\hline \multirow[t]{2}{*}{$L A B S I Z E^{2}$} & -0.070 & -0.009 & -0.075 & -0.010 \\
\hline & $(0.052)$ & $(0.056)$ & $(0.055)$ & $(0.062)$ \\
\hline \multirow[t]{2}{*}{ EXPERIENCE } & $-0.062 * * *$ & -0.007 & $-0.062 * *$ & -0.012 \\
\hline & $(0.030)$ & $(0.030)$ & $(0.031)$ & $(0.032)$ \\
\hline \multirow[t]{2}{*}{ EXPERIENCE $E^{2}$} & 0.001 & 0.000 & 0.001 & 0.000 \\
\hline & $(0.001)$ & $(0.001)$ & $(0.001)$ & $(0.001)$ \\
\hline \multirow[t]{2}{*}{ TTO } & 0.165 & $0.144 * *$ & 0.102 & $0.097^{*}$ \\
\hline & $(0.140)$ & $(0.056)$ & $(0.165)$ & $(0.050)$ \\
\hline \multirow[t]{2}{*}{ TECHS } & 0.005 & 0.000 & 0.005 & 0.000 \\
\hline & $(0.004)$ & $(0.003)$ & $(0.004)$ & $(0.003)$ \\
\hline \multirow[t]{2}{*}{ SENIORSTAFF } & 0.001 & $-0.006^{* * *}$ & 0.000 & $-0.006 * * *$ \\
\hline & $(0.001)$ & $(0.001)$ & $(0.001)$ & $(0.002)$ \\
\hline \multirow[t]{2}{*}{$\ln \left[P U B \_M E A N\right] / \ln \left[C I T p e r P U B \_M E A N\right]$} & $0.630 * * *$ & $0.291 * * *$ & $0.640^{* * *}$ & $0.293 * * *$ \\
\hline & $(0.009)$ & $(0.025)$ & $(0.009)$ & $(0.026)$ \\
\hline \multirow[t]{2}{*}{$\ln \left[P A T \_M E A N\right] / \ln \left[C I T p e r P A T \_M E A N\right]$} & $0.062 * * *$ & $-0.037^{* * *}$ & $0.078 * * *$ & $-0.040 * *$ \\
\hline & $(0.004)$ & $(0.008)$ & $(0.004)$ & $(0.017)$ \\
\hline Log-Likelihood & $-4,963.27$ & $-2,139.29$ & $-4,949.40$ & $-2,115.97$ \\
\hline Joint sign. inst. dum. $\chi^{2}(2)$ & $62.09 * * *$ & $4.59^{*}$ & $59.72 * * *$ & $5.66^{*}$ \\
\hline Joint sign. field dum. $\chi^{2}(6)$ & $12.11 * * *$ & 0.08 & $11.26 * * *$ & 0.03 \\
\hline Joint sign. of county dum. $\chi^{2}$ (15) & $7.91 * *$ & $19.54 * * *$ & $6.97 * *$ & $35.86 * * *$ \\
\hline
\end{tabular}

Notes: Robust standard errors in parentheses are clustered by institution type. All models contain a constant, field, county and institution type dummies. Pre-sample dummies d[X_MEAN] for observations with zero means are not presented. *** (**,*) indicate a significance level of $1 \%(5 \%, 10 \%)$. 
Table 7: Estimation results Poisson Models with fixed effects on patent output (663 obs.)

\begin{tabular}{|c|c|c|c|c|}
\hline & Model 1 & Model 2 & Model 3 & Model 4 \\
\hline Variable & $P A T$ & СITperPAB & $P A T$ & CITperPAT \\
\hline \multirow[t]{2}{*}{ SCIENCE } & -0.025 & $-0.333 * * *$ & -0.023 & $-0.336 * * *$ \\
\hline & $(0.111)$ & $(0.051)$ & $(0.138)$ & $(0.021)$ \\
\hline \multirow[t]{2}{*}{ INSTITUTIONS } & 0.001 & $-0.215 * * *$ & -0.020 & $-0.246 * *$ \\
\hline & $(0.020)$ & $(0.055)$ & $(0.021)$ & $(0.097)$ \\
\hline \multirow[t]{2}{*}{ INDUSTRY } & $-0.202 *$ & -0.057 & & \\
\hline & $(0.113)$ & $(0.138)$ & & \\
\hline \multirow[t]{2}{*}{ LARGE FIRMS } & & & $-0.163 * *$ & 0.013 \\
\hline & & & $(0.068)$ & $(0.158)$ \\
\hline \multirow[t]{2}{*}{ SMEs } & & & $0.083 * * *$ & -0.081 \\
\hline & & & $(0.023)$ & $(0.078)$ \\
\hline \multirow[t]{2}{*}{ PATENTS } & $0.323 * * *$ & $0.564 * * *$ & $0.294 * * *$ & $0.502 * * *$ \\
\hline & $(0.024)$ & $(0.072)$ & $(0.037)$ & $(0.028)$ \\
\hline \multirow[t]{2}{*}{ CONSULTANTS / INDUSTRY_R } & -0.164 & -0.363 & -0.061 & 0.027 \\
\hline & $(0.259)$ & $(0.422)$ & $(0.173)$ & $(0.154)$ \\
\hline \multirow[t]{2}{*}{ STUDENTS } & $2.420 * *$ & $13.336 *$ & $2.024 *$ & 13.654 \\
\hline & $(1.127)$ & $(7.778)$ & $(1.062)$ & $(8.515)$ \\
\hline \multirow[t]{2}{*}{ STUDENTS2 } & $-0.128 *$ & $-0.711 *$ & $-0.111 *$ & $-0.728 *$ \\
\hline & $(0.071)$ & $(0.387)$ & $(0.068)$ & $(0.431)$ \\
\hline \multirow[t]{2}{*}{$L A B S I Z E$} & $0.635 * * *$ & $1.781 * * *$ & $0.590 *$ & $1.765 * * *$ \\
\hline & $(0.230)$ & $(0.208)$ & $(0.312)$ & $(0.225)$ \\
\hline \multirow[t]{2}{*}{$L A B S I Z E^{2}$} & $-0.143 * *$ & $-0.238 * * *$ & $-0.135 *$ & $-0.236 * * *$ \\
\hline & $(0.063)$ & $(0.026)$ & $(0.070)$ & $(0.048)$ \\
\hline \multirow[t]{2}{*}{ EXPERIENCE } & -0.021 & 0.092 & $-0.027 * *$ & $0.108 *$ \\
\hline & $(0.024)$ & $(0.064)$ & $(0.012)$ & $(0.065)$ \\
\hline \multirow[t]{2}{*}{ EXPERIENCE ${ }^{2}$} & 0.000 & $-0.002 *$ & 0.000 & $-0.003 * *$ \\
\hline & $(0.001)$ & $(0.001)$ & $(0.000)$ & $(0.001)$ \\
\hline \multirow[t]{2}{*}{ TTO } & -0.041 & 0.380 & -0.059 & 0.397 \\
\hline & $(0.441)$ & $(0.387)$ & $(0.459)$ & $(0.338)$ \\
\hline \multirow[t]{2}{*}{ TECHS } & -0.001 & $0.020 * * *$ & -0.002 & $0.020 * * *$ \\
\hline & $(0.006)$ & $(0.005)$ & $(0.004)$ & $(0.005)$ \\
\hline \multirow[t]{2}{*}{ SENIORSTAFF } & $0.007 * * *$ & $-0.028 * *$ & $0.008 * * *$ & $-0.028 * * *$ \\
\hline & $(0.001)$ & $(0.012)$ & $(0.002)$ & $(0.010)$ \\
\hline \multirow[t]{2}{*}{$\ln \left[P U B \_M E A N\right] / \ln \left[C I T p e r P U B \_M E A N\right]$} & 0.014 & $0.233 * * *$ & 0.022 & $0.224 * *$ \\
\hline & $(0.117)$ & $(0.082)$ & $(0.095)$ & $(0.097)$ \\
\hline \multirow[t]{2}{*}{$\ln \left[P A T \_M E A N\right] / \ln \left[C I T p e r P A T \_M E A N\right]$} & $0.464 * * *$ & -0.019 & $0.467 * * *$ & -0.008 \\
\hline & $(0.076)$ & $(0.104)$ & $(0.063)$ & $(0.095)$ \\
\hline Log-Likelihood & $-1,079.65$ & -295.00 & $-1,081.95$ & -296.37 \\
\hline Joint sign. inst. dum. $\chi^{2}(2)$ & $87.23 * * *$ & 4.3 & $98.66^{* * *}$ & 4.2 \\
\hline Joint sign. field dum. $\chi^{2}(6)$ & 1.96 & $290.00 * * *$ & 2.28 & $400.00 * * *$ \\
\hline Joint sign. of county dum. $\chi 2$ (15) & $12.55 * * *$ & $411.12 * * *$ & $8.30 * *$ & $476.39 * * *$ \\
\hline
\end{tabular}

Notes: Robust standard errors in parentheses are clustered by institution type. All models contain a constant, field, county and institution type dummies. Pre-sample dummies d[X_MEAN] for observations with zero means are not presented. $* * *(* *, *)$ indicate a significance level of $1 \%(5 \%, 10 \%)$. 


\section{CONCLUSION AND DISCUSSION}

Using data from research units at 46 different universities in Germany, the presented analysis strongly supports the perspective that funding influences the sources of ideas inspiring academic research. In particular, industry sponsoring is associated with a higher impact of industry-influenced ideas on research agendas. More precisely, it increases the role of large firms in the idea generation process. The higher the share of industry funding over the overall budget, the more likely were these research units to report that large firms, but not SMEs, had influenced their research agendas. Grants from public institutions, however, increased utilization of traditional scientific sources and institutional sources of ideas. Further our results suggest that, controlling for unobserved heterogeneity, sourcing ideas from large firms is associated with lower publication and patent output in subsequent periods. Ideas from SMEs on the contrary appear to stimulate patenting without reducing incentives to publish.

Azoulay et al. (2009) point to intra-person economies of scope that emerge when a scientist is involved in both the development of academic and commercial research outcomes that may also be realized when sourcing ideas not only from science but also from industry. Indeed we find that other sources that were categorized as "industrial sources" like exhibitions, trade fairs and TTOs to have a positive impact on publication output. The involvement of a TTO may reduce the individual researchers' burden and hence leave more time for other research projects (Hellman 2007) or may filter ideas with industry relevance that are also valuable for the scientific community.

While we cannot unequivocally state that these associations are causal, our analysis constitutes the first to study the impact of grants on idea-sourcing and its consequences for research productivity. We strongly encourage further research as funding environments continue to shift. OECD data show the share of industry sponsorship is generally rising. Our study focused on research units in Germany, where the share of industry-funded public research increased most significantly over the past decades and amounted to about $25 \%$ in 2007 (OECD 2009). The empirical evidence from Germany suggests that the shift may not be without any consequences for development of science in the long run. However, more research is clearly needed to increase our understanding on how country-level and institution-

level characteristics influence the relationship between sponsorship and research content, and finally research productivity.

Policymakers and scholars in the field of the economics of science face the challenge to assess the nature of ideas that spill over through sponsoring contracts with industry and whether the "idea-sourcing" effect can be distinguished from non-disclosure or delay of 
publication effect. Such an assessment will be necessary in order to judge whether sponsorship from industry is influential enough to threaten the development of science or whether a potential reduction in the number of publications is the price for increased industryscience collaboration that fosters academic inventorship, patentable discoveries and creates benefits that materialize in the private sector. 


\section{BIBLIOGRAPHY}

Agrawal, A. and Henderson, R. (2002), Putting Patents in Context: Exploring Knowledge Transfer from MIT, Management Science 48(1), 44-60.

Amin, M and Mabe, M. (2000), Impact Factors: Use and Abuse, Perspectives in Publishing 1, $1-6$.

Allen, T.H. (1965), Sources of Ideas and Their Effectiveness in Parallel R\&D Projects, Alfred P. Sloan School of Management Working Paper No. 130-65, MIT.

Arundel, A. and Geuna A. (2004), Proximity and the Use of Public Science by Innovative European Firms, Economics of Innovation and New Technology 13(6), 559-80.

Auranen, O. and Nieminen, M. (2010), University Research Funding and Publication Performance - An International Comparison, Research Policy 39, 822-834.

Azoulay, P., Ding, W. and Stuart, T. (2009). The Impact of Academic Patenting on the Rate, Quality and Direction of (Public) Research, The Journal of Industrial Economics 57, 637-676.

Baird, L.M. and Oppenheim, C. (1994), Do Citations Matter?, Journal of Information Science 20, 2-15.

Banal-Estanol, A., Macho-Stadler, I. (2010), Scientific and Commercial Incentives in R\&D: Research vs. Development?, Journal of Economics and Management Strategy 19 (1), $185-221$.

Banal-Estanol, A., Jofre-Bonet, M. and Lawson, C. (2012), The Double-Edged Sword of Industry Collaboration: Evidence from Engineering Academics in the UK, City University London, mimeo.

Benner, M. and Sandström, U. (2000), Institutionalizing the Triple Helix: Research Funding and Norms in the Academic System, Research Policy 29, 291-301.

Bjerregaard, T. (2009), Universities-industry collaboration strategies: a micro-level perspective, European Journal of Innovation Management 12(2), 161 - 176.

Blumenthal, D., Campbell, E., Anderson, M., Causino, N., Louis, K. (1996), Withholding Research Results in Academic Lifescience: Evidence from a National Survey of Faculty, Journal of The American Medical Association 277, 1224-1228.

Blundell, R., R. Griffith and J. van Reenen (1995), Dynamic Count Data Models of Innovation, Economic Journal 105, 333-345.

Blundell, R., Griffith, R. and J. van Reenen (2002), Individual Effects and Dynamics in Count Data Models, Journal of Econometrics 108, 113-131.

Boardman, P.C. and Ponomariov, B.L. (2009), University Researchers Working with Private Companies, Technovation 29, 142-153.

Bodas Freitas, I.M, Geuna, A. and Rossi, F. (2010), The Governance of University-Industry Knowledge Transfer: Why Small Firms do (not) Develop Institutional Collaborations. Working Paper, Turin.

Bogler, R. (1994), The Impact of Past Experience on People's Preference: The Case of University Researchers' Dependency on Funding Sources, Higher Education 28, 169-187.

Bozeman, B. and Gaughan, M. (2007), Impacts of Grants and Contracts on Academic Researchers' Interactions with Industry, Research Policy 36, 694-707. 
Bozeman, B. and Gaughan, M. (2011), How do Men and Women differ in Research Collaborations? An Analysis of the Collaborative Motives and Strategies of Academic Researchers, Research Policy 40, 1393- 1402.

Carayol, N. (2007), Academic incentives and research organization for patenting at a large French university, Economics of Innovation and New Technology 16, 119-138.

Carayol, N. and Matt, M. (2006), Individual and collective determinants of academic scientists' productivity, Information Economics and Policy 18, 55-72.

Cohen, W., Nelson, R., and Walsh, J. (2002), Links and Impacts: The Influence of Public Research on Industrial R\&D, Management Science 48, 1-23.

Colyvas, J.A. and Powell, W.W. (2006), Roads to Institutionalization: The Remaking of Boundaries Between Public and Private Science, Research in Organizational Behavior 27, 305-353.

Czarnitzki, D., K. Hussinger and C. Schneider (2009), Why Challenge the Ivory Tower? New Evidence on the Basicness of Academic Patents, Kyklos 62, 488-499.

Czarnitzki, D, Grimpe, C. and Toole, A. (2011), Does Industry Sponsorship Jeopardize Disclosure of Academic Research?, ZEW Discussion Paper No. 11-009, Mannheim.

Garfield E. and A. Welljams-Dorof (1992), Citation Data: Their Use as Quantitative Indicators for Science and Technology Evaluation and Policy-Making, Science \& Public Policy 19, 321-327.

Geuna, A. (1997), Allocation of Funds and Research Output: the Case of UK Universities, Revue d'Economie Industrielle 79, 143-162.

Geuna, A., Nesta, L., (2006), University Patenting and its Effects on Academic Research: The Emerging European Evidence, Research Policy 35(6), 790-807.

Glenna, L.L., Welsh, R. Ervin, D., Lacy, W.B., and Biscotti, D. (2011) Commercial Science, Scientists' Values, and University Biotechnology Research Agendas, Research Policy 40, 957-968.

Gulbrandsen, M., Smeby, J.C. (2005), Industry Funding and University Professors' Research Performance, Research Policy 34, 932 - 950.

Hall, B.H., A.N. Link, and J.T. Scott (2000), Universities as Research Partners, NBER Working Paper No. 7643.

Hall, B.H., A. Jaffe and M. Trajtenberg (2001), The NBER Patent Citations Data File: Lessons, Insights, and Methodological Tools, NBER Working Paper No. 8498.

Hellman, T. (2007), The Role of Patents for Bridging the Science to Market Gap, Journal of Economic Behavior and Organizations 63, 624-647.

Henderson, R., Jaffe, A. and Trajtenberg, M. (1998), Universities as a Source of Commercial technology: a Detailed Analysis of University Patenting, 1965-1988, Review of Economics and Statistics 80, 119-127.

Hajivassiliou, V. and D. McFadden (1998), The Method of Simulated Scores for the Estimation of LDV Models, Econometrica 66, 863-896.

Hottenrott, H. und S. Thorwarth (2011), Industry Funding of University Research and Scientific Productivity, Kyklos 64(4), 534-555.

Jaffe, A. (1989), Real Effects of Academic Research, American Economic Review 79, 957970. 
Keane, M., (1994), A Computational Practical Simulation Estimator for Panel Data, Econometrica 62, 95-116.

Klevorick, A.K., Levin, R.C., Nelson, R.R. and Winter, S.G. (1995), On the Sources and Significance of Inter-Industry Differences in Technological Opportunities, Research Policy 24(2), 185-205.

Lawson, C. (2012), Academic Patenting: The Importance of Industry Support, City University London and University of Torino, mimeo.

Lee, Y. (2000), The Sustainability of University-Industry Research Collaboration: An Empirical Assessment, Journal of Technology Transfer 25(2), 111-133.

Manjarres-Henriquez, L., Gutierrez-Gracia, A., Carrion-Garcıa, A. and Vega-Jurado, J. (2009), The Effects of University-Industry Relationships and Academic Research On Scientific Performance: Synergy or Substitution?, Research in Higher Education 50, 795-811.

Mansfield, E. (1995), Academic Research Underlying Industrial Innovations: Sources, Characteristics, and Financing, Review of Economics and Statistics 77, 55-65.

Mansfield, E. (1998), Academic Research and Industrial Innovation: an Update of Empirical Findings, Research Policy 26, 773-776.

Mohnen, P. and Hoareau, C. (2003), What Type of Enterprise Forges Close Links with Universities and Government Labs? Evidence from CIS 2, Managerial and Decision Economics 24, 133-146.

Mowery, D.C. (1998), The Changing Structure of the US National Innovation System: Implications for International Conflict and Cooperation in R\&D Policy, Research Policy 27, 639-654.

Narin, F., Hamilton, K.S. and D. Olivastro (1997), The Increasing Linkage between U.S. Technology and Public Science, Research Policy 26, 317-330.

Nelson, R. (1986), Institutions Supporting Technical Advance in Industry, American Economic Review 76, 186-189.

OECD (2009), Business-Funded R\&D in the Higher Education and Government Sectors, in: OECD Science, Technology and Industry Scoreboard 2009. Paris: OECD Publishing.

Perkmann. M. and Walsh, K. (2009), The two Faces of Collaboration: Impacts of UniversityIndustry Relations on Public Research, Industrial and Corporate Change 18(6), 10331065.

Perkmann, M., King, Z. and Pavelin, S. (2011), Engaging Excellence? Effects of Faculty Quality on University Engagement with Industry, Research Policy 40(4), 539-552.

Rappert, B., Webster, A. and Charles, D. (1999), Making Sense of Diversity and Reluctance: Academic-Industrial Relations and Intellectual Property, Research Policy 28(8), 873890.

Roodman, D. (2009), Estimating Fully Observed Recursive Mixed-Process Models with cmp, Center for Global Development, CGD Working Paper 168, Washington D.C.

Rosenberg, N. and Nelson, R. (1994), American Universities and Technical Advance in Industry, Research Policy 23, 323-348.

Rosenberg, N., (1998), Chemical Engineering as a General Purpose Technology, in: Helpman, E. (Ed.), General Purpose Technologies and Economic Growth. Cambridge: MIT Press: 167-192. 
Salter, A. and Martin, B.R. (2001), The Economic Benefits of Publicly Funded Basic Research: a Critical Review, Research Policy 30, 509-532.

Salter, A. and Gann, D. (2003), Sources of Ideas for Innovation in Engineering Design, Research Policy 32, 1309-1324.

Siegel, D.S., Waldman, D. and Link, A. (2003), Assessing the impact of organizational practices on the relative productivity of university Technology Transfer Offices: An Exploratory Study, Research Policy 32, 27-48.

Slaughter, S. and Leslie, L.L. (1997), Academic Capitalism, Baltimore: Johns Hopkins University Press.

Slaughter, S. and Rhoades, G. (2004), Academic Capitalism and the new Economy: Markets, State, and Higher Education, Baltimore: The Johns Hopkins University Press.

Sorenson, O. and L. Fleming (2004), Science and the Diffusion of Knowledge, Research Policy 33, 1615-1633.

Stephan, P.E., Gurmu, S., Sumell, A.J., Black, G. (2007), Who's Patenting in the University? Evidence from the Survey of Doctorate Recipients, Economics of Innovation and New Technology 16, 71-99.

Stern, D.N. and W. Jensen (1983), An Analysis of Publication Productivity of Members of the American Business Law Association, Kyklos 36, 271-280.

Stokes, D. (1997), Pasteur's Quadrant.Washington, D.C.: Brookings Institution Press.

Thursby, J., Thursby, M. and Gupta-Mukherjee, S. (2007), Are There Real Effects of Licensing on Academic Research? A Life Cycle View, Journal of Economic Behavior and Organization 63, 577-598.

Thursby, J. and Thursby, M. (2011), Faculty Participation in Licensing: Implications for Research, Research Policy 40, 20-29.

Train, K. (2009), Discrete Choice Methods with Simulation, Cambridge: Cambridge University Press.

Van Dalen, H. P. and A. Klamer (2005), Is Science A Case of Wasteful Competition?, Kyklos 58, 395-414.

Verspagen, B. (2006), University Research, Intellectual Property Rights and European Innovation Systems, Journal of Economic Surveys 20, 633-690.

Wooldridge J.M. (2002), Econometric Analysis of Cross Section and Panel Data, Cambridge: MIT Press. 
Appendix

Table A.1: Rotated Factor Loadings and Unique Variances

\begin{tabular}{|c|c|c|c|c|c|c|c|c|}
\hline \multirow[b]{2}{*}{ Factors } & \multicolumn{4}{|c|}{ Ordered Variables } & \multicolumn{4}{|c|}{ Binary Variables } \\
\hline & Factor 1 & Factor 2 & Factor 3 & Uniqueness & Factor 1 & Factor 2 & Factor 3 & Uniqueness \\
\hline $\begin{array}{l}\text { Small or Medium-Sized Firms (less than } 250 \\
\text { empl.) }\end{array}$ & -0.004 & 0.682 & -0.011 & 0.5353 & -0.099 & 0.548 & -0.067 & 0.6853 \\
\hline Large Firms (250 empl. or more) & 0.127 & $\mathbf{0 . 5 3 7}$ & -0.037 & 0.6938 & 0.048 & 0.326 & -0.066 & 0.8874 \\
\hline Universities & 0.593 & 0.043 & 0.456 & 0.4386 & 0.441 & 0.007 & 0.537 & 0.5169 \\
\hline Public Research Centres & 0.424 & 0.100 & 0.429 & 0.6266 & 0.229 & -0.010 & 0.495 & 0.7029 \\
\hline Technology Transfer Offices & 0.114 & 0.524 & 0.229 & 0.6599 & -0.019 & 0.397 & 0.158 & 0.8167 \\
\hline Consultants & 0.057 & 0.379 & 0.178 & 0.8212 & 0.066 & 0.129 & -0.038 & 0.9776 \\
\hline Exhibitions and Fairs & 0.189 & 0.637 & 0.104 & 0.5473 & 0.097 & 0.543 & 0.051 & 0.3135 \\
\hline Patents & 0.240 & 0.421 & -0.021 & 0.765 & 0.064 & 0.242 & 0.012 & 0.9372 \\
\hline Academic Journals & 0.900 & 0.038 & -0.025 & 0.1888 & 0.788 & -0.038 & 0.109 & 0.3656 \\
\hline Conferences, Meetings & 0.840 & 0.079 & 0.112 & 0.2757 & 0.825 & 0.024 & 0.072 & 0.6935 \\
\hline Intenet, Media, other Data Bases & 0.630 & 0.223 & 0.190 & 0.5174 & 0.432 & 0.190 & 0.261 & 0.7087 \\
\hline
\end{tabular}

*loadings with absolute value $>0.3$ in bold 
Table A.2: Competitive Funding by Research Field

\begin{tabular}{lcccc}
\hline Field & Freq. & $\%$ & $\begin{array}{c}\text { \% Public Grants } \\
\text { of Total Budget }\end{array}$ & $\begin{array}{c}\text { \% Industry Grants } \\
\text { of Total Budget }\end{array}$ \\
\hline Physics & 106 & 15.99 & 32.643 & 4.241 \\
Mathematics and & 104 & 15.69 & 17.582 & 6.322 \\
$\quad$ Computer Science & 94 & 14.18 & 22.335 & 6.123 \\
Chemistry & 55 & 8.30 & 25.713 & 7.385 \\
Biology & 98 & 14.78 & 15.214 & 11.822 \\
Electrical Engineering & 107 & 16.14 & 22.062 & 14.152 \\
Mechanical Engineering & 99 & 14.93 & 23.425 & 10.265 \\
Other Engineering & 663 & 100.00 & & \\
\hline
\end{tabular}

Table A.3: Scientific Productivity by Research Field (663 obs.)

\begin{tabular}{|c|c|c|c|c|}
\hline & $P U B$ & CITperPUB & $P A T$ & CITperPAT \\
\hline Field & \multicolumn{2}{|c|}{ Publications 1994-1999 } & \multicolumn{2}{|c|}{ Patents 1994-1999 } \\
\hline Physics & 22.47 & 21.74 & 1.11 & 2.97 \\
\hline $\begin{array}{l}\text { Mathematics and } \\
\text { Computer Science }\end{array}$ & 3.97 & 6.57 & 0.21 & 0.56 \\
\hline Chemistry & 27.53 & 16.07 & 1.80 & 5.47 \\
\hline Biology & 11.52 & 21.83 & 0.91 & 3.67 \\
\hline Electrical Engineering & 3.93 & 5.62 & 2.27 & 7.28 \\
\hline Mechanical & 3.46 & 4.99 & 1.84 & 5.65 \\
\hline \multirow[t]{2}{*}{ Other Engineering } & 6.94 & 7.97 & 1.57 & 1.70 \\
\hline & \multicolumn{2}{|c|}{ Publications 2000-2007 } & \multicolumn{2}{|c|}{ Patents 2000-2007 } \\
\hline Physics & 33.29 & 9.45 & 0.91 & 0.20 \\
\hline $\begin{array}{l}\text { Mathematics and } \\
\text { Computer Science }\end{array}$ & 6.50 & 3.61 & 0.25 & 0.02 \\
\hline Chemistry & 39.06 & 8.40 & 1.52 & 0.13 \\
\hline Biology & 19.45 & 9.26 & 1.14 & 0.15 \\
\hline Electrical Engineering & 11.58 & 3.00 & 1.90 & 0.45 \\
\hline Mechanical & 6.54 & 2.31 & 1.91 & 0.26 \\
\hline Other Engineering & 15.33 & 3.78 & 1.79 & 0.20 \\
\hline
\end{tabular}

Table A.3: Correlation coefficients between equations in MV-Probit (see Table 5)

\begin{tabular}{lrrrrrr} 
& Coef. & Rob. S.E. & $\mathbf{z}$ & P>|z & \multicolumn{2}{c}{$[\mathbf{9 5 \%}$ Conf. Interval] } \\
\hline /atanhrho_12 & 0.578 & 0.037 & 15.540 & 0.000 & 0.505 & 0.651 \\
/atanhrho_13 & 0.206 & 0.012 & 17.570 & 0.000 & 0.183 & 0.229 \\
/atanhrho_14 & 0.107 & 0.038 & 2.820 & 0.005 & 0.033 & 0.181 \\
/atanhrho_15 & 0.306 & 0.183 & 1.680 & 0.094 & -0.052 & 0.665 \\
/atanhrho_16 & 0.266 & 0.090 & 2.950 & 0.003 & 0.089 & 0.442 \\
/atanhrho_23 & 0.167 & 0.068 & 2.450 & 0.014 & 0.033 & 0.300 \\
/atanhrho_24 & 0.096 & 0.060 & 1.600 & 0.109 & -0.021 & 0.213 \\
/atanhrho_25 & 0.311 & 0.208 & 1.500 & 0.134 & -0.096 & 0.718 \\
/atanhrho_26 & 0.393 & 0.165 & 2.390 & 0.017 & 0.070 & 0.716 \\
/atanhrho_34 & 0.258 & 0.123 & 2.110 & 0.035 & 0.018 & 0.499 \\
/atanhrho_35 & 0.038 & 0.033 & 1.140 & 0.253 & -0.027 & 0.104 \\
/atanhrho_36 & 0.187 & 0.161 & 1.170 & 0.244 & -0.128 & 0.503 \\
/atanhrho_45 & 0.502 & 0.044 & 11.330 & 0.000 & 0.415 & 0.589 \\
/atanhrho_46 & 0.600 & 0.096 & 6.280 & 0.000 & 0.413 & 0.788 \\
/atanhrho_56 & 0.381 & 0.296 & 1.280 & 0.199 & -0.200 & 0.962 \\
\hline
\end{tabular}

